\title{
Population segments as a tool for health care performance reporting: an exploratory study in the Canadian province of British Columbia
}

Julia M. Langton', Sabrina T. Wong ${ }^{1,2}$, Fred Burge ${ }^{3}$, Alexandra Choi ${ }^{1}$, Niloufar Ghaseminejad-Tafreshi', Sharon Johnston ${ }^{4}$, Alan Katz ${ }^{5}$, Ruth Lavergne ${ }^{6}$, Dawn Mooney ${ }^{1}$, Sandra Peterson ${ }^{1}$ and Kimberlyn McGrail ${ }^{1,7^{*}}$

\begin{abstract}
Background: Primary care serves all age groups and individuals with health states ranging from those with no chronic conditions to those who are medically complex, or frail and approaching the end of life. For information to be actionable and guide planning, there must be some population disaggregation based on differences in expected needs for care. Promising approaches to segmentation in primary care reflect both the breadth and severity of health states, the types and amounts of health care utilization that are expected, and the roles of the primary care provider. The purpose of this study was to assess population segmentation as a tool to create distinct patient groups for use in primary care performance reporting.
\end{abstract}

Methods: This cross-sectional study used administrative data (patient characteristics, physician and hospital billings, prescription medicines data, emergency department visits) to classify the population of British Columbia (BC), Canada into one of four population segments: low need, multiple morbidities, medically complex, and frail. Each segment was further classified using socioeconomic status (SES) as a proxy for patient vulnerability. Regression analyses were used to examine predictors of health care use, costs and selected measures of primary care attributes (access, continuity, coordination) by segment.

Results: Average annual health care costs increased from the low need $(\$ 1460)$ to frail segment $(\$ 10,798)$. Differences in primary care cost by segment only emerged when attributes of primary care were included in regression models: accessing primary care outside business hours and discontinuous primary care ( $\geq 5$ different GP's in a given year) were associated with higher health care costs across all segments and higher continuity of care was associated with lower costs in the frail segment (cost ratio $=0.61$ ). Additionally, low SES was associated with higher costs across all segments, but the difference was largest in the medically complex group (cost ratio $=1.11)$.

(Continued on next page)

\footnotetext{
*Correspondence: kim.mcgrail@ubc.ca

1 Centre for Health Services and Policy Research, The University of British

Columbia (UBC), 201-2206 East Mall, Vancouver, BC V6T 1Z3, Canada

${ }^{7}$ School of Population and Public Health, UBC, Vancouver, BC, Canada

Full list of author information is available at the end of the article
}

(c) The Author(s). 2020 Open Access This article is licensed under a Creative Commons Attribution 4.0 International License, which permits use, sharing, adaptation, distribution and reproduction in any medium or format, as long as you give appropriate credit to the original author(s) and the source, provide a link to the Creative Commons licence, and indicate if changes were made. The images or other third party material in this article are included in the article's Creative Commons licence, unless indicated otherwise in a credit line to the material. If material is not included in the article's Creative Commons licence and your intended use is not permitted by statutory regulation or exceeds the permitted use, you will need to obtain permission directly from the copyright holder. To view a copy of this licence, visit http://creativecommons.org/licenses/by/4.0/ The Creative Commons Public Domain Dedication waiver (http://creativecommons.org/publicdomain/zero/1.0/) applies to the data made available in this article, unless otherwise stated in a credit line to the data. 
(Continued from previous page)

Conclusions: Population segments based on expected need for care can support primary care measurement and reporting by identifying nuances which may be lost when all patients are grouped together. Our findings demonstrate that variables such as SES and use of regression analyses can further enhance the usefulness of segments for performance measurement and reporting.

Keywords: Primary care, Performance measurement, Population segmentation, Risk adjustment, Health care costs, Administrative data

\section{Background}

Routine measurement and reporting can be used to monitor system performance, understand the impact of health care initiatives, identify priorities, and influence health care reform [1-4]. Challenges for primary care performance measurement and reporting include the heterogeneity of patient populations, range of interventions, and intersections with other parts of the health care system $[5,6]$. Primary care serves all age groups and individuals with health states ranging from those with no chronic conditions (who require mostly preventive or episodic care) to those who are medically complex, or frail and approaching the end of life. If information is to be actionable and guide planning and evaluation, there must be some population disaggregation based on differences in expected needs for care.

Segmenting populations based on age or discrete diseases is likely to be insufficient in primary care settings, as such groupings still reflect significant heterogeneity [7]. For instance, two patients living with Congestive Heart Failure (CHF) may have different health care needs because of CHF severity, other comorbid health conditions, and/or complex social circumstances. Similarly, segmenting approaches based solely on high health care costs $[8,9]$ may be limited in the primary care setting as health care costs are typically driven by hospital care and two patients with the same health care expenditures will not necessarily share the same needs from primary care.

Promising approaches to segmentation in primary care reflect both the breadth and severity of health states, the types and amounts of health care utilization that are expected, and the roles of the primary care provider [10]. Segments should be tailored to the needs of information users including patients, providers, and decision makers [11-14], and encompass social determinants of health or vulnerability to enable measurements of health equity given that vulnerable segments of the population have different health care needs compared with the general population [15]. Few studies have incorporated vulnerability into population segments [13, 16] likely because of the complexity and evolving understanding of this construct, and because of the limits of routinely available data to measure it [17]. Using such segments for performance reporting enables comparisons of primary care $[6,10,14,18]$ and quality improvement and/or service planning for particular population sub-groups who stand to benefit most $[8,19-21]$.

The objective of this paper is to add to the developing literature in this area by assessing population segmentation as a tool to create distinct patient groups for use in primary care performance reporting and ultimately quality improvement. Segments that create distinct patient groups in terms of health care needs (overall and for primary care) can be used to support both learning and improvement within practices and health policy planning and decision making. We implemented principles of regional-level primary care performance measurement [18] to develop and test four population segments that reflect low need, multiple morbidity, medical complexity, and frailty. We further segmented the four groups by the best-available measure of socio-economic status (SES) in an attempt to capture some aspects of vulnerability in relation to socioeconomic context. Finally, we selected three exemplar measures that reflect foundational principles of primary care (access, continuity, and coordination) [22] to explore the variability within and across segments and SES stratification, and assess the potential utility of population segments for reporting on primary care performance.

\section{Methods \\ Setting and population}

A cross-sectional observational study using administrate data in the province of British Columbia (BC), Canada which has universal coverage for physician services as determined by the Canada Health Act [23]. BC has a population of $\sim 4.5$ million and the study included all residents meeting the following criteria:

1. $\geq 18$ years as of April 1, 2015

2. Valid records for sex, geographical location [as measured using Local Health Area (LHA [24])] and SES

3. Enrolled in the province's single-payer Medical Services Plan (MSP) for $\geq 75 \%$ of days in each of 2013 / $14,2014 / 15$ and $2015 / 16$ noting that the Canadian fiscal year is April 1 to March 31. 
Note: $\sim 4 \%$ of $\mathrm{BC}$ residents were excluded because they did not meet criterion 2 or 3 .

\section{Data sources}

Administrative data were accessed through Population Data BC [25]. De-identified administrative data files were used to extract data about patient characteristics (consolidation file) [26], physician billings (MSP file) [27], hospital billings (Discharge Abstracts Database, DAD) [28], emergency department visits (National Ambulatory Care Reporting System, NACRS) [29] and medication dispensing (PharmaNet) [30]. For more information about datasets see PopData BC https:// www.popdata.bc.ca/data [31]. This study was approved by the University of British Columbia behavioral research ethics board. All use of data was approved through a Population Data BC data access request [32].

\section{Defining population segments}

Segments were developed based on literature $[6,10,18]$ and input of stakeholders including patients, decisionmakers, and clinicians [33]. Two years of administrative data (fiscal year 2013/14 and 2014/15) were used to create four population segments using a combination of variables: chronic conditions, medical events suggesting medical complexity (e.g. dialysis would be an indicator of complexity among those with a diagnosis of chronic kidney disease), and markers of frailty (Table 1, supplementary file 2). For additional information about the principles and variables used to develop segments, see supplementary file 1 and file 2 .

\section{Socio-economic status (SES)}

Postal codes were converted to quintiles of neighbourhood income adjusted for household size using a conversion file developed and provided by Statistics Canada [35]. Quintiles were ranked from 1 (lowest) to 5 (highest), and then dichotomized into high [3-5] and low [1, 2] SES. Based on previous work [36], neighbourhood income is considered a proxy for SES and for increased vulnerability for poor health (e.g. death) and healthcare outcomes (e.g. more hospitalizations).

\section{Statistical analyses}

We report demographics by population segment and compare healthcare use (physician visits, hospital admissions, and medications) and associated costs in 2015-16 (the year after the population segments were classified).

\section{Distribution of population segments at the practice level}

To examine the distribution of population segments at the level of family physicians, patients were assigned to the primary care physician with whom they had the highest number of ambulatory visits over 3 years (2013/ 14 to 2015/16). In the case of a tie, patients were assigned to the provider with the higher ambulatory billings, and if still tied, to the provider most recently seen. This approach is similar to that used in other studies examining primary care in $\mathrm{BC}$ using administrative data [37]. Additionally, we performed an analysis of primary care physician billings by segment; this analysis included billings for all patients seen by a given family physician (not only patients that were assigned to a physician panel given that some FPs had 0 paneled patients).

\section{Health care use and costs}

Health care use and costs were examined by segment in the 2015-16 year. The main outcome of interest was total cost of care, which includes fee-for-service costs for family physician (FP) care, inpatient hospital care, emergency department (ED) visits, prescription medicine costs, fee-for-service costs for medical and surgical specialist care, and day surgeries. We also present information on health care use associated with costs including the number of FP visits, number of hospital inpatient separations, number of emergency department visits, and number of filled classes of medications (measured at the Anatomical Therapeutic Chemical (ATC) 4th level chemical/therapeutic/pharmacological subgroup).

\section{Selected measures of attributes of primary care}

We selected three exemplar measures of primary care effectiveness, or performance, based Starfield et al.'s definition [38] and previous primary care research in the BC setting [37]. Access to out of hours care and coordination of care were derived using data from 2015/16;

Table 1 Description of four population segments

\begin{tabular}{ll}
\hline Name of segment & Description \\
\hline 1. Low need & $\leq 1$ chronic condition and no event indicating medical complexity \\
2. Multiple morbidities & $\geq 2$ chronic conditions and no event indicating medical complexity \\
3. Medically complex & $\geq 1$ chronic condition and an event indicating complexity that is associated with a chronic condition \\
4. Frail & Aged $\geq 65$, receiving frailty-based care, being deemed palliative, and/or meeting at least two criteria from the Edmonton \\
& frailty scale [34].
\end{tabular}


continuity of care was derived using 3 years of data (2013/14 to $2015 / 16)$.

\section{Access to out of hours FP care}

The percentage of patients with FP billings for visits outside regular office hours, relying on physicians billing for out of hours care.

\section{Continuity of FP care}

We used the usual provider care (UPC) that characterizes the share of total physician visits to a patient's usual FP provider. The UPC index divides the number of ambulatory visits made to the FP who provided the most visits by the total number of ambulatory FP visits for each patient and ranges from 0 to 1.0 with a higher score indicating higher continuity.

\section{Coordination of FP care}

We measured coordination as the percentage of total patients who saw fewer than five FPs in a given year in the ambulatory care setting.

\section{Predicting health care costs}

We employed a two-part Generalized Linear Model stratified by population segment to assess the relationship between several variables [age group, sex, number of chronic conditions (capped at 5; continuous variable), UPC index (continuous variable), and SES (high or low), and 2015/16 costs. Total costs were truncated at the 99th percentile within age and sex groupings to prevent outliers from overly influencing the analysis. Part one of the model predicted which factors were associated with having any health care costs in the 2015/16 year using a logit link and binomial distribution (odds ratios). Part two predicted total costs among those who had $>\$ 0$ costs in the 2015/16 year, using a log link and gamma distribution (cost ratios). Both models included the following variables: age, sex, number of chronic conditions, and SES. In addition, part two of the model include three attributes of primary care: access, continuity, and coordination. We stratified the analyses by population segment because descriptive analysis suggested different relationships between SES and total costs across segments. All statistical analysis was performed using SAS software version 9.4 .

\section{Results}

A total of 3,441,393 people met our eligibility criteria and were included in subsequent analyses. The majority of the population $(82 \%)$ were in the low need population segment (segment 1), while the frail segment (segment 4 ) was the smallest (2\%) (Table 2). Just over $50 \%$ of each segment were female with the exception of segment 4 , where $63 \%$ were female. The proportion of each segment $\geq 75$ years increased from $5 \%$ in segment 1 to $80 \%$ in segment 4 (Table 2). The proportion of people in the low SES group rose steadily from $40 \%$ in segment 1 to $47 \%$ in segment 4 . Note that the sample sizes are reported in each table as they are not uniform across all analyses; please see table footnotes for additional information.

\section{Population segments at the practice level}

Most primary care physicians had patient distributions across population segments that mirrored the overall picture. Others had different mixes of population segments, ranging from those that are virtually all in the healthy segment to a small number that are focused exclusively on complex and/or frail patients (Fig. 1). When we examined physician billings by segment (Fig. 2) the

Table 2 Characteristics of the population by segment, 2015/16

\begin{tabular}{|c|c|c|c|c|c|c|c|c|c|c|c|c|}
\hline & \multicolumn{3}{|c|}{ Segment 1 (82\%) Low need } & \multicolumn{3}{|c|}{$\begin{array}{l}\text { Segment } 2 \text { (13\%) Multiple } \\
\text { morbidities }\end{array}$} & \multicolumn{3}{|c|}{$\begin{array}{l}\text { Segment } 3 \text { (3\%) Medically } \\
\text { complex }\end{array}$} & \multicolumn{3}{|c|}{ Segment 4 (2\%) Frail } \\
\hline & Overall & High SES & LOW SES & Overall & High SES & LOW SES & Overall & High SES & LOW SES & Overall & High SES & LoW SES \\
\hline \# of people & $\begin{array}{l}2,807 \\
725\end{array}$ & $\begin{array}{l}1,697,453 \\
(60.5 \%)\end{array}$ & $\begin{array}{l}1,110,272 \\
(39.5 \%)\end{array}$ & $\begin{array}{l}450 \\
197\end{array}$ & $\begin{array}{l}259,060 \\
(57.5 \%)\end{array}$ & $\begin{array}{l}191,137 \\
(42.5 \%)\end{array}$ & $\begin{array}{l}117 \\
636\end{array}$ & $\begin{array}{l}62,944 \\
(53.5 \%)\end{array}$ & $\begin{array}{l}54,692 \\
(46.5 \%)\end{array}$ & 65,835 & $\begin{array}{l}35,082 \\
(53.3 \%)\end{array}$ & $\begin{array}{l}30,753 \\
(46.7 \%)\end{array}$ \\
\hline \multicolumn{13}{|l|}{ Sex (\%) } \\
\hline Female & 51.2 & 51.3 & 50.9 & 51.1 & 49.7 & 53.0 & 52.8 & 52.8 & 52.8 & 62.7 & 61.8 & 63.8 \\
\hline \multicolumn{13}{|l|}{ Age (\%) } \\
\hline $18-44$ years & 45.9 & 44.3 & 48.4 & 6.0 & 5.6 & 6.5 & 25.5 & 25.2 & 25.7 & . & . & . \\
\hline $45-64$ years & 39.0 & 40.3 & 37.0 & 35.5 & 35.2 & 35.8 & 39.0 & 38.2 & 39.9 & . & & \\
\hline $65-74$ years & 10.0 & 10.6 & 9.2 & 29.2 & 30.2 & 27.8 & 17.5 & 18.4 & 16.5 & 19.9 & 20.0 & 19.8 \\
\hline $75+$ years & 5.1 & 4.8 & 5.4 & 29.4 & 29.0 & 29.9 & 18.0 & 18.1 & 17.8 & 80.1 & 80.0 & 80.2 \\
\hline $\begin{array}{l}\text { \# of Chronic } \\
\text { Conditions (Mean, SD) }\end{array}$ & $\begin{array}{l}0.27 \\
(0.44)\end{array}$ & $0.27(0.45)$ & $0.27(0.44)$ & $\begin{array}{l}2.50 \\
(0.79)\end{array}$ & $\begin{array}{l}2.48 \\
(0.78)\end{array}$ & $\begin{array}{l}2.53 \\
(0.81)\end{array}$ & $\begin{array}{l}2.46 \\
(1.47)\end{array}$ & $\begin{array}{l}2.42 \\
(1.45)\end{array}$ & $\begin{array}{l}2.50 \\
(1.50)\end{array}$ & $\begin{array}{l}2.79 \\
(1.68)\end{array}$ & $\begin{array}{l}2.75 \\
(1.66)\end{array}$ & $\begin{array}{l}2.85 \\
(1.70)\end{array}$ \\
\hline
\end{tabular}

All $p \leq 0.0001$; SES socioeconomic status, low SES income quintiles 1, 2, high SES income quintiles 3, 4, 5 


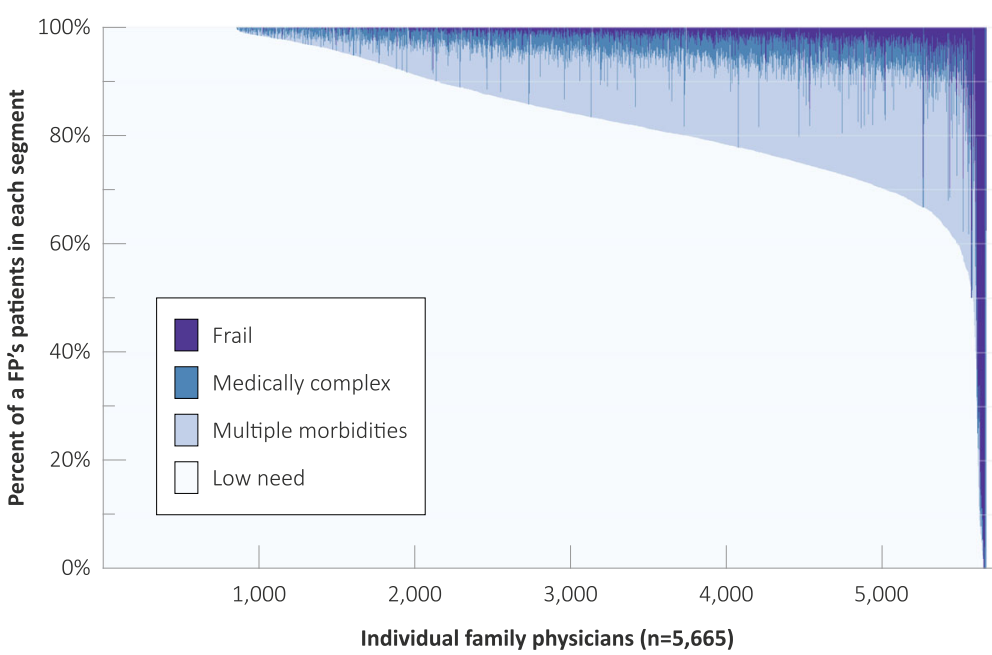

Fig. 1 Family physician patient panels, by segment, 2015/16

pattern was somewhat different in that while just under 1000 physicians had patient panels consisting of $100 \%$ low need patients, there were very few physicians with 100\% costs from low need patients. Comparison of Figs. 1 and 2 demonstrates that physician billings are not proportionate to the breakdown of patient panels by segment. For example, medically complex patients or patients with multiple morbidities account for a disproportionate amount of billings relative to the percentage for these same groups in the physician panels distributions (Fig. 1).

\section{Variation in health services use and costs by segment}

Overall health care costs included hospital costs, ED visits, day surgery, physician visits, and prescription medicines outside the hospital setting. Mean costs per person ranged from $\$ 1460$ in the low need segment to
$\$ 10,798$ in the frail segment (Table 3). Our results suggest that population segmentation creates clear and distinct patient groups in terms of overall healthcare costs.

Costs for the medically complex segment (segment 3 ) were nearly double those of the segment with multiple morbidities (segment 2). The higher costs were driven by segment 3's higher specialist, hospital, and medication costs relative to segment 2; costs for FP visits were similar in both segments. The medically complex and frail segments had similar overall costs but patterns of care were different with the frail segment having comparatively higher costs for hospital services and lower costs for specialist physicians and medications.

Costs were slightly higher $(\sim 5-7 \%)$ in the lower SES group across all segments but the difference was largest in the medically complex group (17\% higher in the low SES

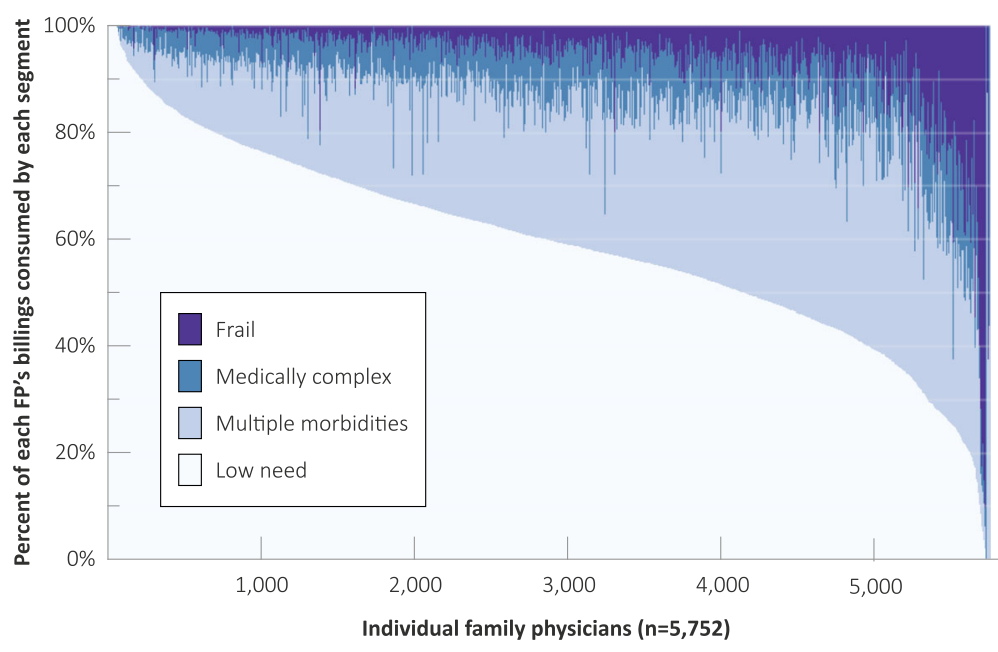

Fig. 2 Family physician billings, by segment, 2015/16 
Table 3 Mean costs and use by health service type, population segment, and SES, 2015/16

\begin{tabular}{|c|c|c|c|c|c|c|c|c|c|c|c|c|}
\hline & \multicolumn{3}{|c|}{$\begin{array}{l}\text { Segment } 1 \text { Low } \\
\text { need }(n=2,807,725)\end{array}$} & \multicolumn{3}{|c|}{$\begin{array}{l}\text { Segment } 2 \text { Multiple morbidities } \\
(n=450,197)\end{array}$} & \multicolumn{3}{|c|}{$\begin{array}{l}\text { Segment } 3 \text { Medically complex } \\
(n=117,636)\end{array}$} & \multicolumn{3}{|c|}{$\begin{array}{l}\text { Segment } 4 \text { Frail } \\
(n=65,835)\end{array}$} \\
\hline & Overall & $\begin{array}{l}\text { High } \\
\text { SES }\end{array}$ & $\begin{array}{l}\text { Low } \\
\text { SES }\end{array}$ & Overall & High SES & Low SES & Overall & High SES & Low SES & Overall & $\begin{array}{l}\text { High } \\
\text { SES }\end{array}$ & $\begin{array}{l}\text { LoW } \\
\text { SES }\end{array}$ \\
\hline \multicolumn{13}{|l|}{ Mean Costs (\$) } \\
\hline Total FP Care (any location) & 185 & 181 & 191 & 602 & 580 & 632 & 657 & 627 & 692 & 907 & 889 & 927 \\
\hline Cost of Specialist Care & 222 & 224 & 219 & 742 & 750 & 731 & 1431 & 1401 & 1465 & 828 & 846 & 808 \\
\hline Inpatient Hospital Care & 421 & 389 & 470 & 2203 & 2075 & 2378 & 5130 & 4625 & 5712 & 6741 & 6505 & 7011 \\
\hline Day surgeries & 117 & 123 & 108 & 350 & 361 & 335 & 364 & 373 & 354 & 204 & 218 & 189 \\
\hline ED visit (estimated facility cost) & 103 & 95 & 116 & 223 & 207 & 245 & 433 & 380 & 495 & 352 & 334 & 372 \\
\hline $\begin{array}{l}\text { Prescription Medicines (PharmaCare } \\
+ \text { Private paid) }\end{array}$ & 411 & 405 & 421 & 1702 & 1663 & 1755 & 2766 & 2605 & 2951 & 1766 & 1731 & 1805 \\
\hline Total Costs ${ }^{\mathrm{a}}$ & 1460 & 1418 & 1525 & 5822 & 5636 & 6075 & 10,782 & 10,010 & 11,670 & 10,798 & $\begin{array}{l}10 \\
523\end{array}$ & $\begin{array}{l}11 \\
112\end{array}$ \\
\hline \multicolumn{13}{|l|}{ Use (\#) } \\
\hline FP visits (any location) & 4.5 & 4.4 & 4.7 & 11.7 & 11.3 & 12.3 & 13.9 & 13.2 & 14.7 & 19.6 & 19.3 & 20.1 \\
\hline $\begin{array}{l}\text { Hospital separations per } 100 \\
\text { population }\end{array}$ & 5.4 & 5.1 & 5.9 & 19.7 & 18.7 & 20.9 & 41.5 & 37.2 & 46.5 & 47.7 & 45.9 & 49.7 \\
\hline ED Visits per 100 population & 35.3 & 32.6 & 39.4 & 76.2 & 70.7 & 83.7 & 147.9 & 129.5 & 168.9 & 120.0 & 114.0 & 126.9 \\
\hline Filled classes of medication & 2.4 & 2.4 & 2.4 & 7.3 & 7.1 & 7.6 & 8.5 & 8.2 & 8.8 & 9.1 & 8.9 & 9.3 \\
\hline \multicolumn{13}{|c|}{ Selected attributes of primary care measures } \\
\hline \multicolumn{13}{|l|}{ Access } \\
\hline $\begin{array}{l}\text { Access outside office hours: \% } \\
\text { patients with FP billing outside } \\
\text { office hours }\end{array}$ & 2.6 & 2.5 & 2.7 & 4.2 & 4.0 & 4.4 & 6.0 & 5.8 & 6.3 & 9.3 & 9.0 & 9.7 \\
\hline \multicolumn{13}{|l|}{ Continuity of Care } \\
\hline UPC Index (Mean, range 0-1) & 0.7 & 0.7 & 0.7 & 0.8 & 0.8 & 0.8 & 0.7 & 0.7 & 0.7 & 0.8 & 0.8 & 0.8 \\
\hline \multicolumn{13}{|l|}{ Coordination } \\
\hline$\%$ patients seeing $<5$ FP physicians & 95.2 & 95.4 & 95.0 & 91.8 & 92.2 & 91.3 & 88.1 & 88.6 & 87.6 & 93.2 & 93.5 & 93.0 \\
\hline
\end{tabular}

All $p<0.05, E D$ emergency department, FP family physician, SES socioeconomic status (low SES income quintiles 1, 2, high SES income quintiles 3, 4, 5.); UPC usual provider of care

${ }^{\text {a }}$ Total costs includes: Total FP Care, inpatient hospital care, prescription medicines, plus medical \& surgical specialist care, day surgeries and ED visits

group). In the medically complex low SES group, hospital costs were the main drivers of increased expense.

\section{Attributes of care by segment}

The percentage of patients accessing FPs outside of regular office hours ranged from $2.6 \%$ of patients in the low need segment to $9.3 \%$ in the frail segment (Table 3). Continuity of care, as measured by UPC, was fairly stable across all segments despite the highest volume of FP use in the frail segment; however, arguably this measure may mean different things for different segments (Table 3). For example, a continuity score for the frail segment (that had the highest volume of FP use) may mean something different than the same continuity score for segments with lower volumes of FP care. There were subtle differences in coordination of care, measured as the percentage of patients seeing fewer than 5 FPs. This percentage was highest in the low need segment (95.2\%) and lowest in the medically complex segment (88.1\%).
There were minimal differences in attributes of primary care by SES.

\section{Prediction of overall costs}

The regression analyses demonstrated that for all segments, increasing age is associated with an increased likelihood of incurring health care costs (Table 4, Fig. 3) and with higher costs among health care users (Table 5, Fig. 3). Females have an increased likelihood of incurring any health care costs, but among those with costs, females have lower costs across all but the low need segment.

Across all segments, those in lower SES quintiles were less likely to use health care services (Table 4, Fig. 3) but had higher costs among the users (Table 5, Fig. 3). The exception was the frail group, which showed limited variability across SES.

The regression analyses demonstrate that those with a higher number of chronic conditions were more likely to 
Table 4 Logistic regression of use (vs. no use ${ }^{a}$ ) of healthcare in BC residents, 2015/16

\begin{tabular}{|c|c|c|c|c|}
\hline \multicolumn{5}{|l|}{ Odds Ratio (OR) (LCL - UCL) } \\
\hline & $\begin{array}{l}\text { Segment } 1 \text { Low need } \\
(\mathrm{n}=2,558,276)\end{array}$ & $\begin{array}{l}\text { Segment } 2 \text { Multiple } \\
\text { morbidities }(n=449,925)\end{array}$ & $\begin{array}{l}\text { Segment } 3 \text { Medically } \\
\text { complex }(n=116,821)\end{array}$ & $\begin{array}{l}\text { Segment } 4 \text { Frail } \\
(n=65,661)\end{array}$ \\
\hline \multicolumn{5}{|l|}{ Age (years) } \\
\hline $18-44$ & $0.52(0.51-0.53)$ & $0.42(0.36-0.49)$ & $0.57(0.46-0.71)$ & $\mathrm{n} / \mathrm{a}$ \\
\hline $45-64$ & $0.63(0.61-0.64)$ & $0.69(0.61-0.77)$ & $0.83^{*}(0.67-1.04)$ & $\mathrm{n} / \mathrm{a}$ \\
\hline $65-74$ & ref & ref & ref & ref \\
\hline $75+$ & $1.19(1.15-1.23)$ & $0.84(0.74-0.96)$ & $0.83^{*}(0.63-1.09)$ & $1.02 *(0.82-1.26)$ \\
\hline \multicolumn{5}{|l|}{ Sex } \\
\hline Female & $2.13(2.11-2.15)$ & $1.67(1.53-1.83)$ & $2.08(1.84-2.35)$ & $1.16^{*}(0.97-1.40)$ \\
\hline Male & ref & ref & ref & ref \\
\hline $\begin{array}{l}\text { Number of chronic conditions }(0-5+) \text { : } \\
\text { continuous variable }\end{array}$ & $4.67(4.60-4.74)$ & $2.05(1.87-2.25)$ & $1.76(1.63-1.90)$ & $1.45(1.36-1.55)$ \\
\hline \multicolumn{5}{|l|}{ SES } \\
\hline Low & $0.95(0.94-0.96)$ & $0.77(0.70-0.84)$ & $0.87(0.77-0.98)$ & $0.93^{*}(0.78-1.11)$ \\
\hline High & ref & ref & ref & ref \\
\hline
\end{tabular}

${ }^{*} p \geq 0.05$, all other $p<0.05, L C L$ lower confidence limit, UCL upper confidence limit; SES socioeconomic status (Iow SES income quintiles 1,2 , high SES income quintiles $3,4,5$.)

${ }^{a}$ No health care use is defined as $\$ 0$ in health care costs in 2015/16.The number of individuals with $\$ 0$ in health care costs in $2015 / 16$ varies by segment: Segment $1=264,375$; Segment $2=2035$; Segment $3=1095$; Segment $4=505$

${ }^{b}$ Note that this table excludes individuals with no FP visits in the 3 years of data used to create the continuity of care measure (UPC). The number of people excluded varies by segment: Segment $1=249,449$; Segment $2=272$; Segment $3=815$; Segment $4=174$

${ }^{c}$ Number of chronic conditions was treated as a continuous variable given that the number of chronic conditions varies by segment (e.g., by definition, segment 1 has fewer chronic conditions than segment 4); please see Supplementary File 3 (Table 1a and b) for analyses where chronic conditions were treated as categorical variables; we note that this did not change our findings

use health care services (Table 4, Fig. 3) and had higher costs among the users (Table 5, Fig. 3). To test for the linearity of this effect, we ran a logistic regression model with number of chronic conditions as categorical (Supplementary File 3, Table 1a and b). This analysis did not substantively change our findings except for showing that those in segment 3 and 4 with a smaller number of chronic conditions $(0-1)$ were less likely to use health care services and have lower costs among the users. These additional analyses also showed that the addition of one chronic condition had different implications in terms of health care use and costs for different segments. For example, an increase from zero to one chronic condition in segment 1 was associated with an increased likelihood of health care use and costs among the users and the magnitude of this effect seemed to be larger than an increase of one chronic condition (for example, an increase from 3 to 4 or 4 to 5 chronic conditions) in the more complex segments [2 through 4]. For segments 2 through 4, the association between number of chronic conditions and health care use and costs was relatively linear.

In terms of the attributes of primary care, continuity of care was associated with lower costs for frail population segment only (cost ratio $=0.61$ ). Out of regular office hours FP visits were associated with higher health care costs across all segments, and the magnitude of this effect was largest in the low need segment (cost ratio =
3.91). Finally, coordination of care (seeing fewer than 5 FPs in a given year) was associated with lower costs across all segments and the magnitude of this effect was greatest for the low need segment. In other words, disorganized care (seeing 5 or more FPs) is associated with higher costs.

\section{Discussion}

Four mutually exclusive and exhaustive population segments designed to capture need for primary health care services are distributed differently across physician practices, suggesting that these segments may help understand variations in practice-level costs and patterns of care. These population segments showed expected variation in terms of use/costs of health care services while differences in measures of attributes of primary care were not as pronounced as expected. Consistent with previous studies, we found that a small proportion of the population accounts for the largest proportion of overall health care costs [8]. As patient complexity increases, variation within population segments of health care costs also increase with the medically complex and frail segments having the greatest variation in health care costs. Our proxy measure for SES shows that lower income is associated with lower likelihood of access to health care, but higher use among those who have any use; this is largely consistent with existing Canadian [39] and international [40] literature. Our finding that low SES was 


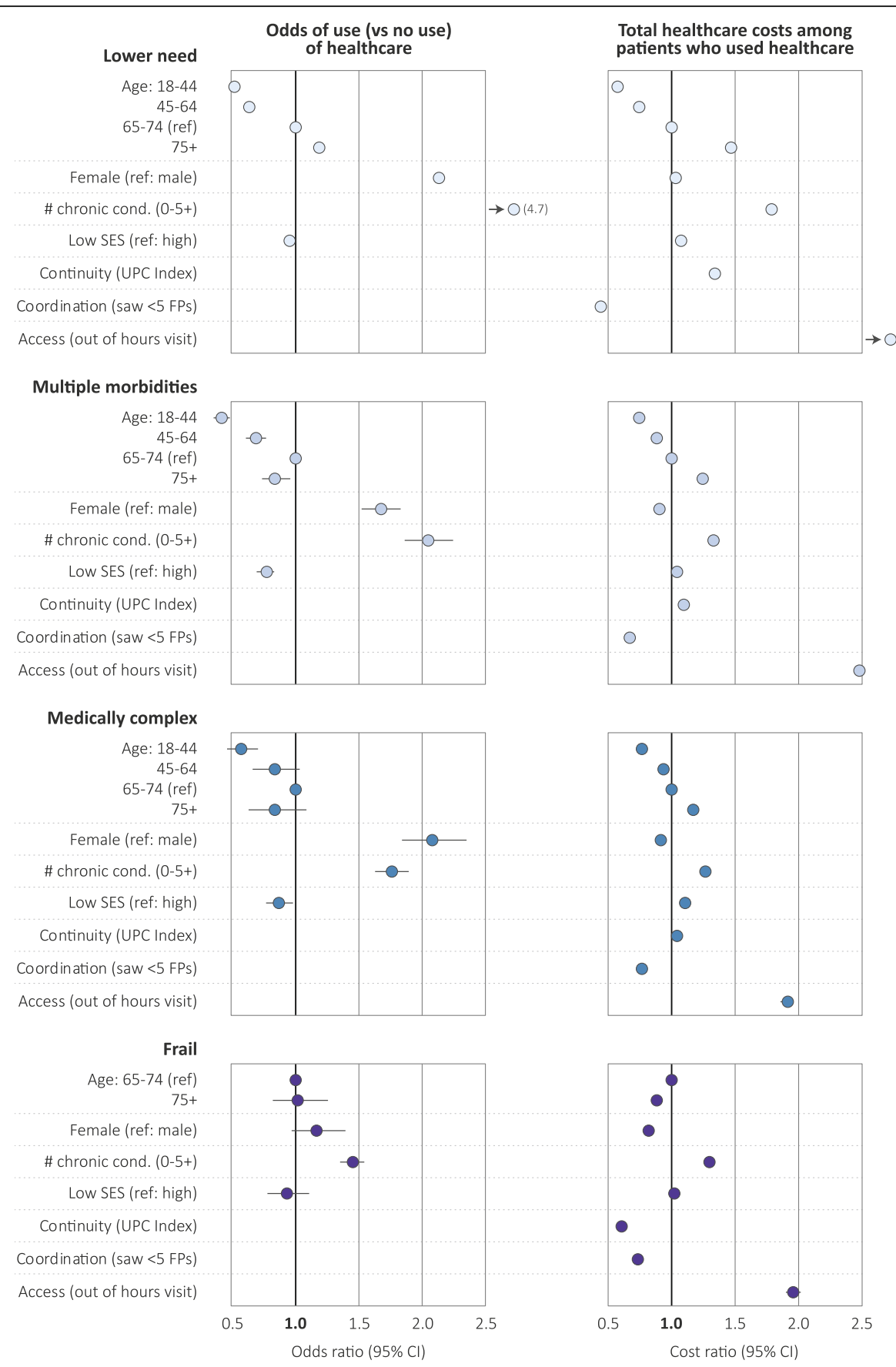

Fig. 3 Logistic regression results, stratified by segment, 2015/16

associated with higher costs across all segments but more pronounced in the medically complex segment is consistent with other research that suggests that SES plays a role in managing changes in health status and leads to health inequities [41, 42].

Age and number of chronic conditions were associated with health care costs but the patterns were different by segment suggesting that population segments provide nuanced information about health care use/costs [43].
This also suggests that age or number of chronic conditions does not always predict increased health care costs and that segments could be a useful value-add for better addressing otherwise unmeasured constructs that affect health and healthcare use. Given that segments were defined using 2 years of data and health care costs/primary care attributes were examined in the subsequent year, segments may be a useful tool to anticipate health system needs and to inform system planning. Using 
Table 5 Total healthcare costs among patients who used the BC healthcare system, 2015/16 ${ }^{\mathrm{a}}$

\begin{tabular}{|c|c|c|c|c|}
\hline \multicolumn{5}{|l|}{ Cost Ratio (CR) (LCL - UCL) } \\
\hline & $\begin{array}{l}\text { Segment } 1 \text { Low need } \\
(n=2,293,901)\end{array}$ & $\begin{array}{l}\text { Segment } 2 \text { Multiple } \\
\text { morbidities }(n=447,890)\end{array}$ & $\begin{array}{l}\text { Segment } 3 \text { Medically } \\
\text { complex }(n=115,726)\end{array}$ & $\begin{array}{l}\text { Segment } 4 \text { Frail } \\
(n=65,156)\end{array}$ \\
\hline \multicolumn{5}{|l|}{ Age (years) } \\
\hline $18-44$ & $0.57(0.56-0.57)$ & $0.75(0.74-0.76)$ & $0.77(0.75-0.78)$ & $\mathrm{n} / \mathrm{a}$ \\
\hline $45-64$ & $0.74(0.74-0.75)$ & $0.88(0.87-0.88)$ & $0.94(0.92-0.96)$ & $\mathrm{n} / \mathrm{a}$ \\
\hline $65-74$ & ref & ref & ref & ref \\
\hline $75+$ & $1.47(1.45-1.48)$ & $1.24(1.23-1.25)$ & $1.17(1.15-1.19)$ & $0.88(0.86-0.90)$ \\
\hline \multicolumn{5}{|l|}{ Sex } \\
\hline Female & $1.03(1.03-1.03)$ & $0.90(0.90-0.91)$ & $0.91(0.90-0.93)$ & $0.82(0.81-0.84)$ \\
\hline Male & ref & ref & ref & ref \\
\hline $\begin{array}{l}\text { Number of chronic conditions }(0-5+) \text { : } \\
\text { continuous variable }\end{array}$ & $1.79(1.79-1.80)$ & $1.33(1.32-1.33)$ & $1.27(1.26-1.28)$ & $1.30(1.30-1.31)$ \\
\hline \multicolumn{5}{|l|}{ SES } \\
\hline Low & $1.07(1.06-1.07)$ & $1.04(1.03-1.05)$ & $1.11(1.09-1.12)$ & $1.02(1.00-1.04)$ \\
\hline High & ref & ref & ref & ref \\
\hline Continuity index (UPC) & $1.34(1.33-1.35)$ & $1.09(1.07-1.10)$ & $1.04(1.01-1.07)$ & $0.61(0.58-0.64)$ \\
\hline \multicolumn{5}{|l|}{ Coordination: number of FPs } \\
\hline Saw $<5$ FPs & $0.45(0.45-0.46)$ & $0.67(0.66-0.68)$ & $0.77(0.75-0.78)$ & $0.73(0.70-0.76)$ \\
\hline Saw $>=5 \mathrm{FPs}$ & ref & ref & ref & ref \\
\hline \multicolumn{5}{|l|}{ Access: out-of-hours FPs } \\
\hline Yes & $3.91(3.87-3.94)$ & $2.48(2.44-2.52)$ & $1.91(1.86-1.96)$ & $1.96(1.90-2.02)$ \\
\hline No & ref & ref & ref & ref \\
\hline
\end{tabular}

${ }^{*} p \geq 0.05$, all other $p<0.05$; LCL lower confidence limit, UCL upper confidence limit, FP family physician, SES socioeconomic status, UPC usual provider of care ${ }^{a}$ As in Table $4 a$, this table excludes individuals with no FP visits in the 3 years of data used to create the continuity of care measure (UPC). This table also excludes individuals with $\$ 0$ costs in 2015/16 which varies by segment: Segment 1=264,375; Segment $2=2035$; Segment $3=1095$; Segment $4=505$

${ }^{b}$ Number of chronic conditions was treated as a continuous variable given that the number of chronic conditions varies by segment (e.g., by definition segment 1 has fewer chronic conditions than segment 4); please see Supplementary File 3 (Table 1a and b) for analyses where chronic conditions were treated as categorical variables; we note that this did not change our findings

segments for this purpose means that interventions can be aimed at service needs for particular groups rather than targeting interventions based on single medical conditions.

Variations in the attributes of primary care across segments further underline the potential utility of disaggregated reporting. For example, the relationship between out-of-office care and higher costs in the healthy and frail segments might point to different underlying issues; for healthier individuals this may reflect a need for better coordination of services and/or structure of office hours, while for frail individuals, out-of-office care may be a necessary component of care for their complex needs. However, we note that future research should test the utility of the segments for other important attributes of primary care such as effectiveness, patient-centeredness, and comprehensiveness [38, 44].

Health system planners could use information on population segments at the community or regional level to provide and tailor supports to primary care clinicians and regions. For example, primary care population segments provide an opportunity for resourcing collaborative interdisciplinary healthcare teams and integrated team pathways, particularly for practices with a disproportionate percentage of complex and/or frail patients [45]. Integrative approaches and sharing of responsibility and accountability could address some of the unique challenges within the different segments [46].

Our analyses relied on administrative data and are subject to the usual limits of data that are not collected specifically for research purposes such as a lack of clinical information and time lags in data access. Generally, administrative data are retrospective and if such an approach is to be used to influence decision making, it will be important to move towards real-time analyses and effectively track the highest need, most vulnerable populations [47]. Administrative data are population-based but mainly capture fee-for-service primary care services. It would be useful to examine other models of primary care such as capitation [48] using population segments given the expected differences in need for service across segments. We constructed four population segments and there are of course many other options for defining specific segments of interest and further research should 
address the robustness of these findings when applied to different population segment definitions in other jurisdictions [6-8]. Our approach would be strengthened by linking administrative data with other data sources to capture elements of performance such as patientreported outcome and experience measures to more accurately capture patient needs and experiences, examine factors such as the presence of carers and social supports, patient behaviours and traits that may be more predictive of health care needs than medical complications [19]. Having access to these data sets would enable us to enhance our definition of vulnerability, as our SES measure (based on postal code) only scratched the surface of vulnerability [17].

\section{Conclusion}

In conclusion, these four distinct population segments have potential utility for primary care performance measurement and reporting. Our approach could be used to develop and tailor information on primary care performance for different groups such as health care providers and decision makers such that segments could be used for practice management and quality improvement efforts. This information also provides a useful springboard for further in-depth analyses that help elucidate the underlying causes of variations in care.

\section{Supplementary information}

Supplementary information accompanies this paper at https://doi.org/10. 1186/s12875-020-01141-w.

\section{Additional file 1: Supplementary File 1.}

Additional file 2: Supplementary File 2. Definitions for chronic conditions and complications to derive segments 2, 3 and 4 .

Additional file 3: Supplementary File 3. Regression analysis model with chronic conditions as a categorical variable.

\section{Abbreviations}

ATC: Anatomical therapeutic chemical; BC: British Columbia; CHF: Congestive heart failure; CR: Cost Ratio; DAD: Discharge abstracts database; ED: Emergency department; FP: Family physician; LHA: Local health area; MSP: Medical services plan; NACRS: National Ambulatory Care Reporting System; PREMS: Patient reported experience measures; PROMS: Patient reported outcome measures; PopData BC: Population Data BC; SES: Socioeconomic status; UPC: Usual provider care

\section{Acknowledgements}

All inferences, opinions, and conclusions drawn in this study are those of the authors, and do not reflect the opinions or policies of the Data Steward(s).

\section{Authors' contributions}

Authors JL, SW, KM, DM, SP were involved in the design and conception of the study; SP, KM, RL, JL, SW led the data collection and analysis; JL, SW, FB, AC, NGT, SJ, AK, RL, SP, KM were involved in the interpretation of findings. All authors were involved in drafting the manuscript and have read and approved the final version of this manuscript.

\section{Funding}

This research was funded by the Canadian Institutes of Health Research (grant number TTF-128265) and the Michael Smith Foundation for Health
Research (grant number PT-CPH-00001-134). The funders had no role in the design of the study, data collection and analysis, interpretation of the data or writing of the manuscript.

\section{Availability of data and materials}

The data that support the findings of this study are available from Population Data BC (https://www.popdata.bc.ca/) but restrictions apply to the availability of these data, which were used for the current study under Data Stewards' approval and Research Agreements with Data Stewards, and so are not publicly available. Data are however available from Population

Data BC upon reasonable request and with permission of the Data Stewards.

\section{Ethics approval and consent to participate}

This study was approved by the University of British Columbia behavioral research ethics board (H13-01237). All use of data was approved through a Population Data BC data access request.

Consent for publication

Not applicable.

\section{Competing interests}

None declared.

\section{Author details}

${ }^{1}$ Centre for Health Services and Policy Research, The University of British Columbia (UBC), 201-2206 East Mall, Vancouver, BC V6T 1Z3, Canada. ${ }^{2}$ School of Nursing, UBC, Vancouver, Canada. ${ }^{3}$ Department of Family Medicine, Dalhousie University, Halifax, NS, Canada. ${ }^{4}$ Department of Family Medicine, University of Ottawa, Ottawa, ON, Canada. ${ }^{5}$ Department of Family Medicine and Community Health Sciences, University of Manitoba, Winnipeg, MB,

Canada. ${ }^{6}$ Faculty of Health Science, Simon Fraser University, Burnaby, BC, Canada. ${ }^{7}$ School of Population and Public Health, UBC, Vancouver, BC, Canada.

Received: 23 July 2019 Accepted: 14 April 2020

Published online: 31 May 2020

References

1. Adair CE, Simpson E, Casebeer AL, Birdsell JM, Hayden KA, Lewis S. Performance measurement in healthcare: part II--state of the science findings by stage of the performance measurement process. Healthc Policy. 2006;2(1):56-78.

2. Adair CE, Simpson E, Casebeer AL, Birdsell JM, Hayden KA, Lewis S. Performance measurement in healthcare: part I--concepts and trends from a state of the science review. Healthc Policy. 2006;1(4):85-104.

3. Cipriano PF. Population health management: a formula for value. Nurs Manag. 2017:48(2):22-4.

4. Cassel CK, Conway PH, Delbanco SF, Jha AK, Saunders RS, Lee TH. Getting more performance from performance measurement - NEJM. N Engl J Med. https://doi.org/10.1056/NEJMp1408345.

5. Primary Health Care in Canada: A Chartbook of Selected Indicator Results, 2016. 2016.

6. Lynn J, Straube BM, Bell KM, Jencks SF, Kambic RT. Using population segmentation to provide better health care for all: the "bridges to health" model. Milbank Q. 2007:85(2):185-208 discussion 209-12.

7. Low LL, Yan S, Kwan YH, Tan CS, Thumboo J. Assessing the validity of a data driven segmentation approach: A 4 year longitudinal study of healthcare utilization and mortality. Abe T, ed. PLoS One. 2018;13(4): e0195243. https://doi.org/10.1371/journal.pone.0195243.

8. Wodchis WP, Austin PC, Henry DA. A 3-year study of high-cost users of health care. CMAJ. 2016;188(3):182-8. https://doi.org/10.1503/cmaj.150064.

9. The Commonwealth Fund. High-Need, High-Cost Patients: Who Are They and How Do They Use Health Care? | Commonwealth Fund. https://www. ncbi.nlm.nih.gov/pubmed/27571599.

10. Porter ME, Pabo EA, Lee TH. Analysis \& commentary redesigning primary care: a strategic vision to improve value by organizing around patients' needs. Health Aff. 2013. https://doi.org/10.1377/hlthaff.2012.0961.

11. Wills J, Crichton N, Lorenc A, Kelly M. Using population segmentation to inform local obesity strategy in England. Health Promot Int. 2015;30(3):65866. https://doi.org/10.1093/heapro/dau004. 
12. Li Y, Berenson J, Moran AE, Pagan JA. Who does not reduce their sodium intake despite being advised to do so? A population segmentation analysis. Prev Med (Baltim). 2017;99:77-9. https://doi.org/10.1016/j.ypmed.2017.01.017.

13. Dixon J, Spencelayh E, Howells A, Mandel A, Gille F. Indicators of quality of Care in General Practices in England: an independent review for the secretary of state for health. London: The Health Foundation; 2015. Available at: https:// wuw.health.org.uk/sites/default/files/IndicatorsOfQualityOfCarelnGeneralPractices InEngland.pdf. Accessed July 2018.

14. Vuik SI, Mayer EK, Darzi A. Patient segmentation analysis offers significant benefits for integrated care and support. Health Aff. 2016:35(5):769-75. https://doi.org/10.1377/hlthaff.2015.1311.

15. Kringos DS, Boerma WGW, Hutchinson A, van der Zee J, Groenewegen PP. The breadth of primary care: a systematic literature review of its core dimensions. BMC Health Serv Res. 2010;10(1):65. https://doi.org/10.1186/1472-6963-10-65.

16. Long P, Abrams M, Milstein A, Anderson G, Lewis Apton K, Lund Dahlberg M, Whicher D, Editors. Effective Care for High-Need Patients: Opportunities for Improving Outcomes, Value, and Health. Washington, DC: National Academy of Medicine. 2017.

17. Clark B, Preto N. Exploring the concept of vulnerability in health care. Can Med Assoc J. 2018;190(11):E308 LP-E309. https://doi.org/10.1503/cmaj.180242.

18. Langton JM, Wong ST, Johnston S, et al. Primary care performance measurement and reporting at a regional level: could a matrix approach provide actionable information for policy makers and clinicians? Healthc Policy. 2016;12(2):33-51. https://www.ncbi.nlm.nih.gov/pubmed/28032823.

19. Loeb DF, Binswanger IA, Candrian C, Bayliss EA. Primary care physician insights into a typology of the complex patient in primary care. Ann Fam Med. 2015;13(5):451-5. https://doi.org/10.1370/afm.1840.

20. Figueroa JF, Joynt Maddox KE, Beaulieu N, Wild RC, Jha AK. Concentration of potentially preventable spending among high-cost Medicare subpopulations. Ann Intern Med. 2017;167(10):706. https:/doi.org/10.7326/M17-0767.

21. Joynt KE, Figueroa JF, Beaulieu N, Wild RC, Orav EJ, Jha AK. Segmenting high-cost Medicare patients into potentially actionable cohorts. Healthcare. 2017;5(1-2):62-7. https://doi.org/10.1016/J.HJDSI.2016.11.002.

22. Starfield B. Primary care: balancing health needs, services, and technology. New York: Oxford University Press; 1998.

23. Canada Health Act (Consolidation). Canada; 1985.

24. Ministry of Jobs; Trade and Technology - BC Stats; Local Health Area Boundaries. https://catalogue.data.gov.bc.ca/dataset/local-health-areaboundaries. Accessed Feb 2019.

25. Hertzman CP, Meagher N, McGrail KM. Privacy by Design at Population Data BC: a case study describing the technical, administrative, and physical controls for privacy-sensitive secondary use of personal information for research in the public interest. J Am Med Informatics Assoc. 2013;20(1):25-8. https://doi.org/10.1136/amiajnl-2012-001011.

26. British Columbia Ministry of Health [creator]. Consolidation File (MSP Registration \& Premium Billing). Data Extract. MOH (2015): Population Data BC [publisher]; 2015.

27. British Columbia Ministry of Health [creator]. Medical Services Plan (MSP) Payment Information File. Data Extract. MOH (2015): Population Data BC [publisher]; 2015.

28. Canadian Institute for Health Information [creator]. Discharge Abstract Database (Hospital Separations). Data Extract. MOH (2015): Population Data BC [publisher]; 2015.

29. Canadian Institute for Health Information [creator]. National Ambulatory Care Reporting System (NACRS). Data Extract. MOH (2015): Population Data BC [publisher]; 2015.

30. British Columbia Ministry of Health [creator]. PharmaNet. Data Extract. $\mathrm{MOH}$ (2015): Population Data BC [publisher]; 2015.

31. Population Data BC. Data available. https://www.popdata.bc.ca/data. Accessed Feb 2019.

32. Population Data BC. The Data Access Request (DAR) process | www. popdata.bc.ca. Accessed Feb 2019.

33. Langton J, McGrail K, Wong ST. A Matrix Approach to Primary Care Performance Measurement: Developing a High Quality Information System Aligned with Modern Primary Care Practice [workshop summary paper]; 2015. http://chspr.sites.olt.ubc.ca/files/2016/04/PHC-performancemeasurement-workshop-summary-2015.pdf. Accessed July 2018.

34. Urquhart R, Giguere AMC, Lawson B, et al. Rules to identify persons with frailty in administrative health databases*. Can J Aging. 2017;36(4):1-8. https://doi.org/10.1017/S0714980817000393.
35. Statistics Canada. Postal code OM conversion file plus (PCCF+) (82F0086X). 2013. https://www150.statcan.gc.ca/n1/en/catalogue/82F0086X

36. Wilkins R. Use of postal codes and addresses in the analysis of health data. Heal Rep. 1993:5(2):157-77.

37. Lavergne MR, Peterson S, McKendry R, Sivananthan S, McGrail K. Full-service family practice in British Columbia: policy interventions and trends in practice, 1991-2010. Healthc Policy. 2014;9(4):32-47.

38. Starfield B, Shi L, Macinko J. Contribution of primary care to health systems and health. Milbank Q. 2005;83(3):457-502. https://doi.org/10.1111/j.14680009.2005.00409.x

39. McGrail KM. Income-related inequities: Cross-sectional analyses of the use of medicare sorvices in British Columbia in 1992 and 2002. Open Med. 2008; 2(4):e91-8. https://www.ncbi.nlm.nih.gov/pubmed/21602958.

40. Van Doorslaer E, Masseria C, OECD Health Equity Research Group. IncomeRelated Inequality in the Use of Medical Care in 21 OECD Countries : Policy Studies from the OECD Health Project. 2004. https://www.oecd.org/els/ health-systems/31743034.pdf.

41. Ford-Gilboe M, Wathan C, Varcoe C, Herbert C, Jackson B. How equityoriented health care affects health: key mechanisms and implications for primary health care practice and policy. Milbank Q. 2018;96(4):635-71. https://doi.org/10.1111/1468-0009.12349.

42. Canadian Institute of Health Information $(\mathrm{CIHI})$. Trends in Income-Related Health Inequalities in Canada. Ottawa, 2015. https://secure.cihi.ca/free_ products/trends_in_income_related_inequalities_in_canada_2015_en.pdf. Accessed Feb 2019

43. Clough JD, Riley GF, Cohen M, et al. Patterns of care for clinically distinct segments of high cost Medicare beneficiaries. Healthcare. 2016;4(3):160-5. https://doi.org/10.1016/j.hjdsi.2015.09.005.

44. Wong ST, Langton JM, Katz A, et al. Promoting cross-jurisdictional primary health care research: developing a set of common indicators across 12 community-based primary health care teams in Canada; 2018. https://doi. org/10.1017/S1463423618000518

45. Papapanagiotou P, Fleuriot J, Grando A. Rigorous process-based modelling of patterns for collaborative work in healthcare teams. In: 2012 25th IEEE international symposium on computer-based medical systems (CBMS). Rome: Institute of Electrical and Electronics Engineers; 2012. https://doi.org/ 10.1109/CBMS.2012.6266330.

46. Coventry P, Lovell K, Dickens C, Bower P, Chew-Graham C. Integrated primary care for patients with mental and physical multimorbidity: cluster randomised controlled trial of collaborative care for patients with depression comorbid with diabetes or cardiovascular disease. BMJ. 2015;350. https://doi.org/10.1136/bmj.h638.

47. Haggerty J, Chin MH, Katz A, et al. Proactive strategies to address health equity and disparities: recommendations from a bi-National Symposium. J Am Board Fam Med. 2018;31(3):479-83. https://doi.org/10.3122/jabfm.2018. 03.170299 .

48. Glazier RH, Klein-Geltink J, Kopp A, Sibley LM. Capitation and enhanced feefor-service models for primary care reform: a population-based evaluation. Can Med Assoc J. 2009;180(11):E72-81. https://doi.org/10.1503/cmaj.081316.

\section{Publisher's Note}

Springer Nature remains neutral with regard to jurisdictional claims in published maps and institutional affiliations.

Ready to submit your research? Choose BMC and benefit from:

- fast, convenient online submission

- thorough peer review by experienced researchers in your field

- rapid publication on acceptance

- support for research data, including large and complex data types

- gold Open Access which fosters wider collaboration and increased citations

- maximum visibility for your research: over $100 \mathrm{M}$ website views per year

At $\mathrm{BMC}$, research is always in progress.

Learn more biomedcentral.com/submission 